\title{
Performance Comparison of a Dual-Ridge Horn Antenna and a Planar Monopole Antenna in the Microwave Breast Cancer Detection
}

\author{
Ali R. Celik', Muhammed B. Kurt² \\ ${ }^{1,2}$ Department of Electrical and Electronics Engineering, University of Dicle, Diyarbakir, Turkey \\ Corresponding author: Ali R. Celik (e-mail: ali.celik@dicle.edu.tr)
}

\begin{abstract}
Detection of the breast cancer tumors at an early stage is very crucial for a successful treatment. Microwave measurement systems have gained attention for this aim over the past decades. This paper, firstly mentions the main techniques used for breast cancer detection. Then the microwave measurement system is introduced and the advantages of using microwaves in detection are given. After that, some simulation and experimental studies are presented to detect tumors. The main purposes of these measurements are demonstrating a simple microwave breast cancer detection system and comparing the performances of the previously designed and proposed planar monopole antenna (PMA) to a dual-ridge horn (DRH) antenna in the system. These antennae are ultra-wideband (UWB) and directional. They have a narrow beamwidth and stable directional pattern in the interval of 3-10 GHz. For the measurements, a material with a low dielectric constant to represent the healthy tissue and another material with a high dielectric constant to represent the tumor are used. The return loss results show that the reflection differences for the case of presence and absence of tumor are more apparent in the PMA measurements than the DRH measurements. Hence, according to the results of this study, the performance of the compact-sized PMA is better than the DRH with a larger size.
\end{abstract}

INDEX TERMS Breast cancer, microwave measurement, scattering parameters, ultra-wideband antenna.

\section{INTRODUCTION}

Jowadays, detecting breast cancer at an early stage is one 1 of the important challenges in medical imaging. There are several techniques used for this purpose such as the mammography, digital tomosynthesis, magnetic resonance imaging (MRI) and ultrasound techniques. X-rays are electromagnetic waves in the energy range $0.125-125 \mathrm{keV}$ and wavelength ranging from 10 to 0.01 nanometers, that is, their frequency ranges from 30 to $30.000 \mathrm{PHz}$ [1]. In the Xray mammography method, data are converted into electrical signals through detectors. These signals are sent to the computer screen or, if necessary, printed as an X-ray film. Mammography provides high-resolution images but it is not highly reliable. It has false-negative or false-positive rates. It also requires painful and uncomfortable breast compression and exposes the patient to ionizing radiation [2].

In the digital tomosynthesis method, a large number of breast images is taken at different angles and the images are obtained in 3D in the form of millimeter sections [3]. This technology has a lower radiation level than mammographies along with the advantages of less compression and less pain. However, it is a very expensive technology. There are also some disadvantages such as the use of large sensors in measurements and the difficulty of adjusting the position.
MRI is a method of converting signals obtained by stimulating and vibrating hydrogen atoms with waves in a strong magnetic field and resonating them into images. This method is not very suitable for routine breast screening due to its uncomfortable procedures [4].

In the ultrasound method, images are obtained by touching the transducer, which has a transmitter and receiver feature, on the breast skin and measuring the reflection of high sound waves $(5-15 \mathrm{MHz})$ sent to the breast surface. Wavelengths ranging from 10-300 microns provide sufficient resolution for detection of breast cancer. However, this technology is less effective than mammography. The other disadvantage of ultrasound is its inability to produce high detection for deep and condensed tissue structures such as fatty tissues. Moreover, the ultrasound technique requires high skills and a long time. Thus, it is used as a supportive method in addition to mammography [5].

As understood, the current methods of detecting the breast tumors do not meet the ideal requirements even with the combined use of the mammography, tomosynthesis, MRI and ultrasound techniques. Therefore, researchers are actively searching for alternative modalities of screening and diagnosing breast cancer. One of the leading alternative methods for this aim is the microwave measurement method. 
Microwaves are defined in the electromagnetic spectrum in the frequency range of $0.3-300 \mathrm{GHz}$. These frequencies show apparent differences in the electrical properties of healthy breast tissue and malignant tumors such as relative permittivity (dielectric constant) and conductivity [7]. This system uses nonionizing radiation which is significantly safer than ionizing radiation used in mammography. Furthermore, compression is not needed in this technique, which makes its examinations more comfortable for the patient [6,7]. Another advantage of this method is its low cost.

Among several microwave detection methods, the approach based on using ultra-wideband (UWB) radar signals has recently attracted considerable attention. A key component and one of the biggest challenges of this method is the antenna. For a successful system, the antenna must have the following requirements [8]:

- UWB signal radiation to transmit short pulses,

- compact size and narrow half power beamwidth (HPBW) for focusing on the target material,

- good impedance matching across the entire band to transmit most of the energy,

- stable and directional radiation pattern through the frequency band to obtain high front-to-back ratio.

In summary, radar-based UWB microwave measurement systems require UWB, compact, stable and directive antenna as their sensor.

In a previous study [9], a planar circular disc monopole antenna (PCDMA) was developed for using in these systems. In another study [10], some experimental measurements for a microwave breast tumor detection system were made to investigate the performance of the PCDMA.

The aim and novelty of this study is making comparison between the performance of the small-sized PCDMA and a factory-made dual-ridge horn (DRH) antenna with a large size. The DRH was chosen for comparison because it is a known standard for wideband applications.

Thanks to having an average gain of $8.5 \mathrm{~dB}$ throughout the operating range of broad frequency, this antenna is optimal for transmitting and receiving wideband pulses. In order to make a comparison, a similar measurement procedure used in the study [10] was repeated in this study. Furthermore, some simulation measurements in the frequency domain which were not shown in that study are given here.

\section{MATERIALS AND METHOD}

\section{A. PCDMA AND DRH ANTENNA}

In the study [9], a compact-sized antenna including a circular patch and an L-shaped ground plane was designed and proposed for the measurement system. In the design process, a parasitic element was added to the patch side, and a triangular slot and two small notches were etched on the ground plane in order to improve the bandwidth and directivity of the antenna.
The simulated and measured $\mathrm{S}_{11}$ of the antenna demonstrated that it had a working frequency band from 3 $\mathrm{GHz}$ to $10 \mathrm{GHz}$. The good stability of the directional radiation patterns was obtained in this frequency range. The direction of the maximum radiation moved between $\varphi=54$ and $\varphi=32$ degrees and HPBW decreased from 56 degrees to 30 degrees through the frequency band. The directivity changed between $6.2 \mathrm{~dB}$ and $9.4 \mathrm{~dB}$ in the interval of 3-10 GHz. Accordingly, the proposed antenna was suitable for usage in the radar-based UWB microwave breast cancer detection method thanks to its good characteristics such as being small, UWB, highly and stably directive. The view of the proposed PCDMA and the radiation patterns in $x-y$ plane are shown in Fig. 1.

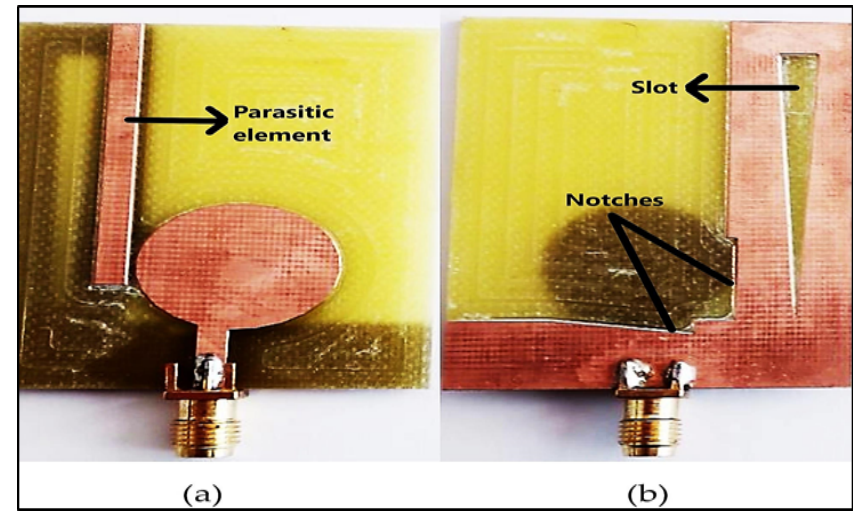

(a)

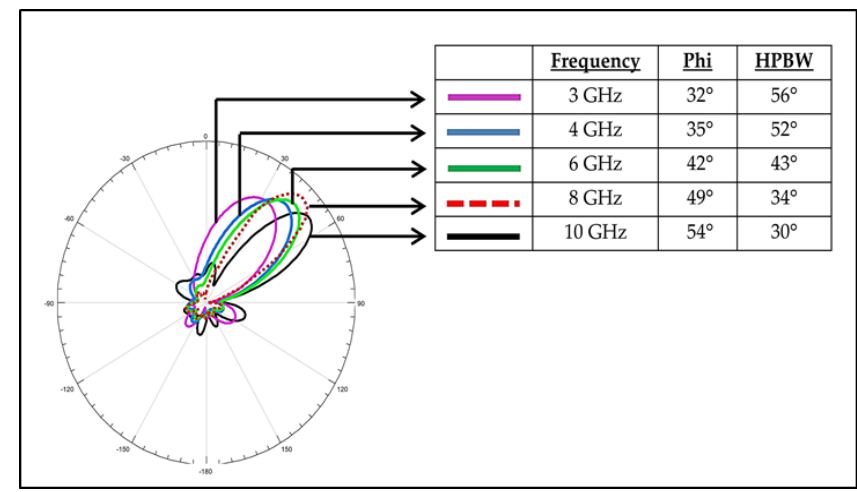

(b)

FIGURE 1. a) Front and back view of the PCDMA proposed in [9], b) Beam variation versus frequency for the proposed antenna.

As mentioned before, the commercial DRH antenna was chosen in this study for comparison because it is a known standard for wideband applications. It has the working frequency band from $1 \mathrm{GHz}$ to $18 \mathrm{GHz}$. A good stability of the directional radiation patterns is obtained in this frequency range. Moreover, the HPBW of the DRH decreases from 52 degrees to 24 degrees and the gain changes between $5 \mathrm{~dB}$ and $14 \mathrm{~dB}$ in the range of 1-18 GHz [11]. The Amitec DRH20 antenna that was used in this study is shown in Fig. 2. 


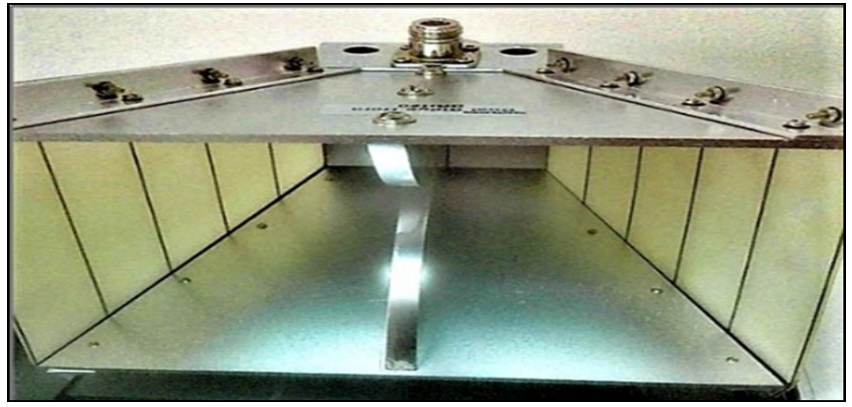

FIGURE 2. Amitec DRH20 dual-ridge horn antenna

There are many antenna designs with wide-bandwidth, compact size, high directivity and low HPBW that have been proposed for medical imaging, radar systems, see-throughwall imaging and $\mathrm{C}$ and $\mathrm{X}$-band operations. The comparison of the properties of the used PCDMA and DRH with to the antennae reported in the studies [12-30] is given in Table I.

\section{B. BREAST PHANTOM}

For the measurements, a simple planar breast phantom with the dimensions of $15 \mathrm{~cm} \times 5 \mathrm{~cm} \times 7 \mathrm{~cm}$ was used to mimic the relative permittivity $\left(\boldsymbol{\varepsilon}_{\mathbf{r}}\right)$ and conductivity $(\boldsymbol{\sigma})$ of the actual breast tissue. The electrical parameters of biological tissues in the human body are variable according to frequency. In the studies [31,32], the $\boldsymbol{\varepsilon}_{\mathrm{r}}$ and $\boldsymbol{\sigma}$ of normal breast are assumed to be of 9 and $0.4 \mathrm{~S} / \mathrm{m}$, respectively, whereas they are assumed to be 50 and $4 \mathrm{~S} / \mathrm{m}$ for malignant breast tissue.
Since the antenna proposed and used in this study operates in the frequency range of 3-10 $\mathrm{GHz}$, an average frequency value of $7 \mathrm{GHz}$ was chosen and electrical properties in this fixed frequency were taken as reference. At this frequency, the $\boldsymbol{\varepsilon}_{\mathbf{r}}$ and $\boldsymbol{\sigma}$ of normal breast are assumed to be of 4.8 and $0.5 \mathrm{~S} / \mathrm{m}$, respectively, whereas they are assumed to be 64 and $11 \mathrm{~S} / \mathrm{m}$ for malignant breast tissue [33,34].

In the phantom, canola oil with $\boldsymbol{\varepsilon}_{\mathrm{r}}$ of 4 and $\boldsymbol{\sigma}$ of $0.3 \mathrm{~S} / \mathrm{m}$ at $7 \mathrm{GHz}[35,36]$ was used as a fat-mimicking material. Additionally, a small object $(6 \mathrm{~mm})$ was selected for mimicking a tumor. This object was in the form of a plastic cylinder filled with sea-water with an $\boldsymbol{\varepsilon}_{\mathbf{r}}$ of 69 and $\boldsymbol{\sigma}$ of 9 $\mathrm{S} / \mathrm{m}$ at $7 \mathrm{GHz}$ [37], and it was placed inside the phantom with similar techniques to those reported in previous studies [3739].

\section{SIMULATION PROGRAM AND MEASUREMENT DEVICES}

The simulation measurements were made with the aid of the commercially available software High Frequency Structural Simulation (HFSS) which based on the full-wave finite elements method and widely used in the analysis of electromagnetic structures [40].

In the experimental measurements, a $10 \mathrm{kHz}-20 \mathrm{GHz}$ Vector Network Analyzer (VNA) and extension cables were used to send the microwave signals and measure the reflections from the breast phantom. Prior to the measurements, the VNA was calibrated over 3-10 $\mathrm{GHz}$ using a one-port $\left(\mathrm{S}_{11}\right)$ calibration procedure [41].

TABLE I. Comparison of the performance of the used antennas with the antennas reported in some previous work

\begin{tabular}{|c|c|c|c|c|c|c|}
\hline Reference Antenna & Size $(\mathbf{m m})$ & Frequency Band(GHz) & Bandwidth(\%) & HPBW $\left({ }^{\circ}\right)$ & Gain(dB) & Directivity(dB) \\
\hline Proposed PCDMA & $55 \times 40$ & $3.0-10.0$ & 108 & $56-30$ & $6.0-8.4$ & $6.2-9.4$ \\
\hline DRH20 & $560 \times 210 \times 180$ & $1.0-18.0$ & 179 & $52-24$ & $5.0-14.0$ & $--{ }^{1}$ \\
\hline$[12]$ & $50 \times 50$ & $6.0-8.0$ & 28 & $47-37$ & ---1 & $7.5-8.0$ \\
\hline$[13]$ & $50 \times 50$ & $3.1-11.0$ & 112 & ---1 & $4.3-10.8$ & $--{ }^{1}$ \\
\hline [14] & $50 \times 46$ & $3.1-12.6$ & 120 & $75-25$ & $4.0-8.0$ & ---1 \\
\hline$[15]$ & $102 \times 102$ & $0.4-1.0$ & 85 & $--^{1}$ & $2.4-5.8$ & $--{ }^{1}$ \\
\hline$[16]$ & $32 \times 30$ & $4.2-8.5$ & 68 & $78-43$ & $5.2-9.3$ & ---1 \\
\hline$[17]$ & $50 \times 50$ & $4.0-9.0$ & 77 & $56-25$ & $7.0-10.0$ & ---1 \\
\hline$[18]$ & $30 \times 21$ & $6.8-7.3 \& 9.7-11.7$ & --- & $--{ }^{1}$ & $1.0-5.5$ & ---1 \\
\hline [19] & $40 \times 26$ & $1.0-8.0$ & 155 & ---1 & $--{ }^{1}$ & $--{ }^{1}$ \\
\hline$[20]$ & $50 \times 50$ & $4.1-11.5$ & 95 & $49-22$ & $2.5-8.4$ & $--{ }^{1}$ \\
\hline [21] & $32 \times 32$ & $9.7-14.5$ & 39 & $35-26$ & $4.0-10.7$ & ---1 \\
\hline [22] & $50 \times 40$ & $3.0-8.0$ & 91 & $60-40$ & $5.0-6.8$ & $5.2-7.8$ \\
\hline [23] & $62.5 \times 62.5$ & $2.0-4.0$ & 66 & ---1 & ---1 & ---1 \\
\hline [24] & $50 \times 50$ & $2.75-11.0$ & 126 & ---1 & ---1 & ---1 \\
\hline [25] & $36 \times 36$ & $2.5-10.4$ & 122 & ---1 & $1.0-9.0$ & ---1 \\
\hline [26] & $40 \times 40$ & $3.6-8.0$ & 76 & ---1 & $3.8-7.0$ & ---1 \\
\hline [27] & $73.5 \times 42$ & $3.0-10.0$ & 108 & ---1 & $2.5-10.0$ & ---1 \\
\hline [28] & $27.3 \times 14$ & $4.5-10.5$ & 80 & ---1 & $--{ }^{1}$ & ---1 \\
\hline [29] & $63 \times 51$ & $2.5-8.5$ & 109 & ---1 & $2.0-7.5$ & ---1 \\
\hline [30] & $80 \times 44$ & $2.4-18.0$ & 153 & ---1 & ---1 & ---1 \\
\hline
\end{tabular}

${ }^{1}:$ Not reported 


\section{CONFIGURATION OF THE MEASUREMENT SYSTEM}

Throughout the measurements, the DRH and PCDMA were placed at a distance of $20 \mathrm{~mm}$ over top of the phantom. Firstly, the measurements were made without a tumor. Then, the tumor-mimicking object was placed at the center of the rectangular phantom as shown in Fig. 3 (a) and (b). After that, it was placed at a deeper point $(45 \mathrm{~mm}$ distance from the surface) for the other measurement as seen in Fig. 3 (c).
Fig. 3 (d) also shows the top view of the phantom. Since the beam direction of the PCDMA moved from $\varphi=54$ to $\varphi=32$ degrees, the antenna was positioned so that the direction of the radiation was as perpendicular as possible to the phantom.

The 3D plot of the radiation pattern with the antenna for the frequency of $7 \mathrm{GHz}$ which corresponded to $\varphi=45^{\circ}$ is shown in Fig. 3 (b) for demonstration.

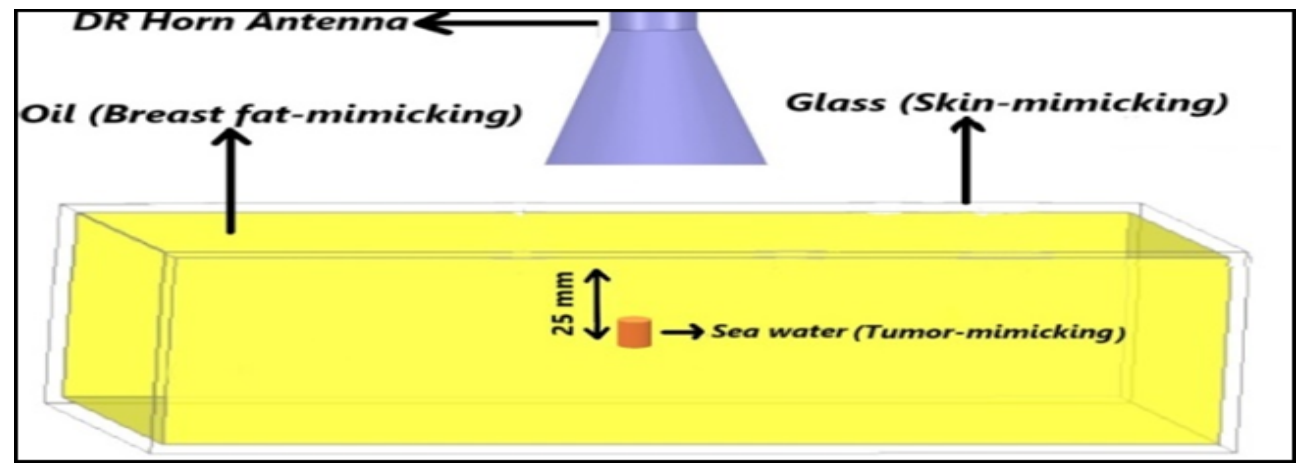

(a)

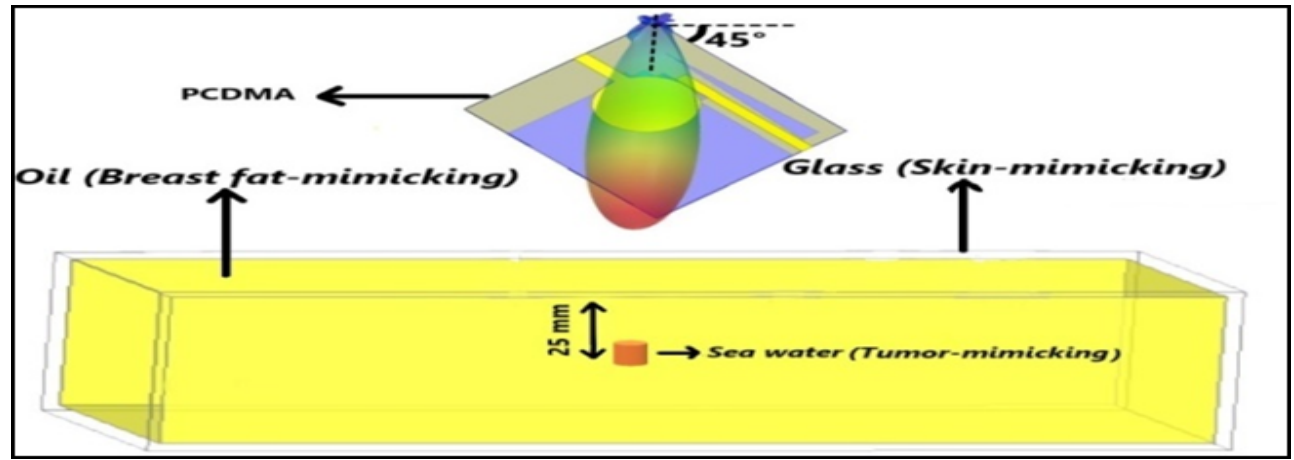

(b)

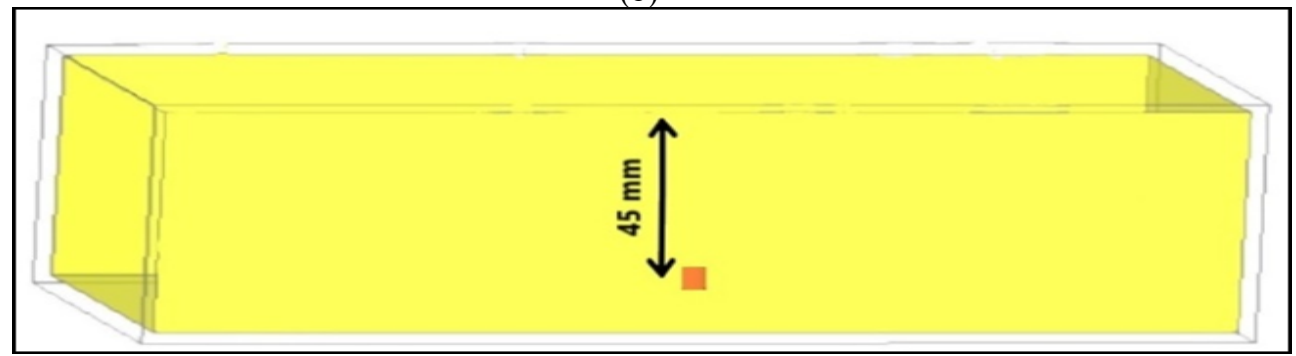

(c)

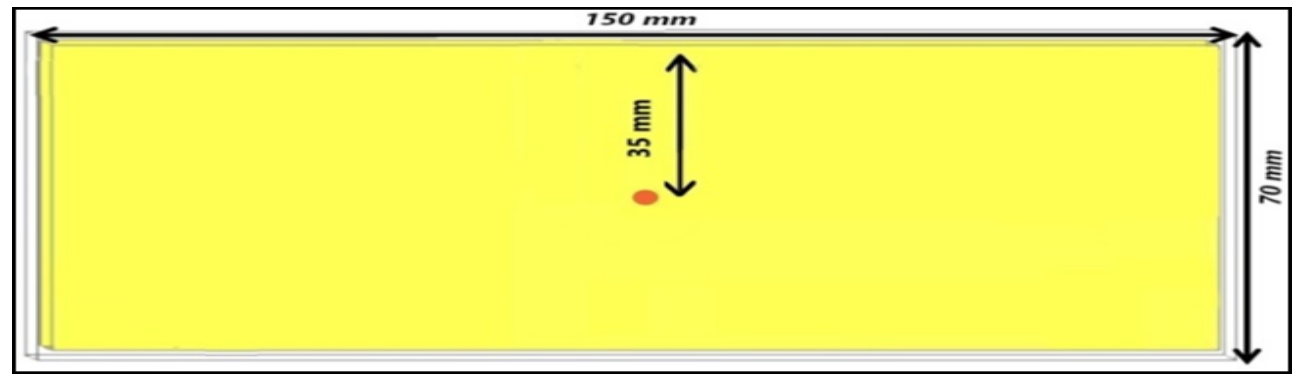

(d)

FIGURE 3. a) Front view of the phantom with the tumor and DRH antenna, b) Front view of the phantom with the tumor and PCDMA,

c) Front view of the phantom when tumor is at the depth of $45 \mathrm{~mm}, \mathrm{~d}$ ) Top view of the phantom with tumor. 


\section{MEASUREMENT RESULTS AND DISCUSSIONS}

\section{A. SIMULATION MEASUREMENTS AND RESULTS}

Firstly, simulation measurements were made without a tumor in the phantom. Then, the tumor-mimicking object was located at the center of the phantom, and the measurements were made in the HFSS program.
The simulated $S_{11}$ results obtained by the antennae are shown in Fig. 4 (a) and (b), respectively. These results are given for the cases of the phantom having a tumor and not having a tumor in it. The results for the tumorous cases are also plotted at the same graphic in Fig. 4 (c) for comparison of the PCDMA and DRH.

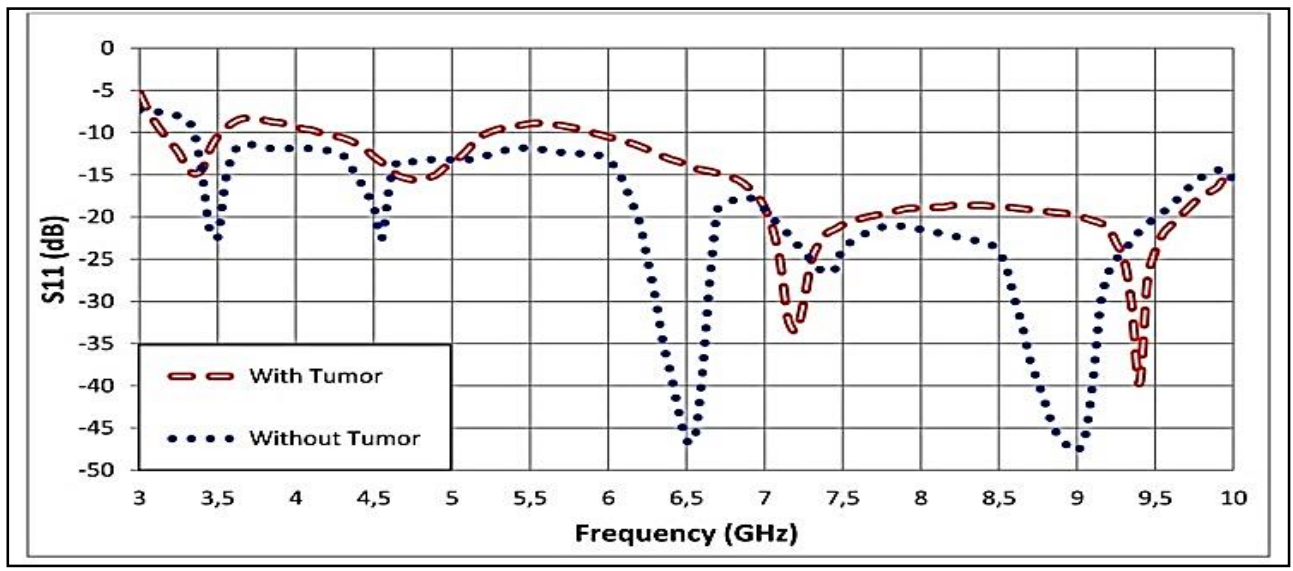

(a)

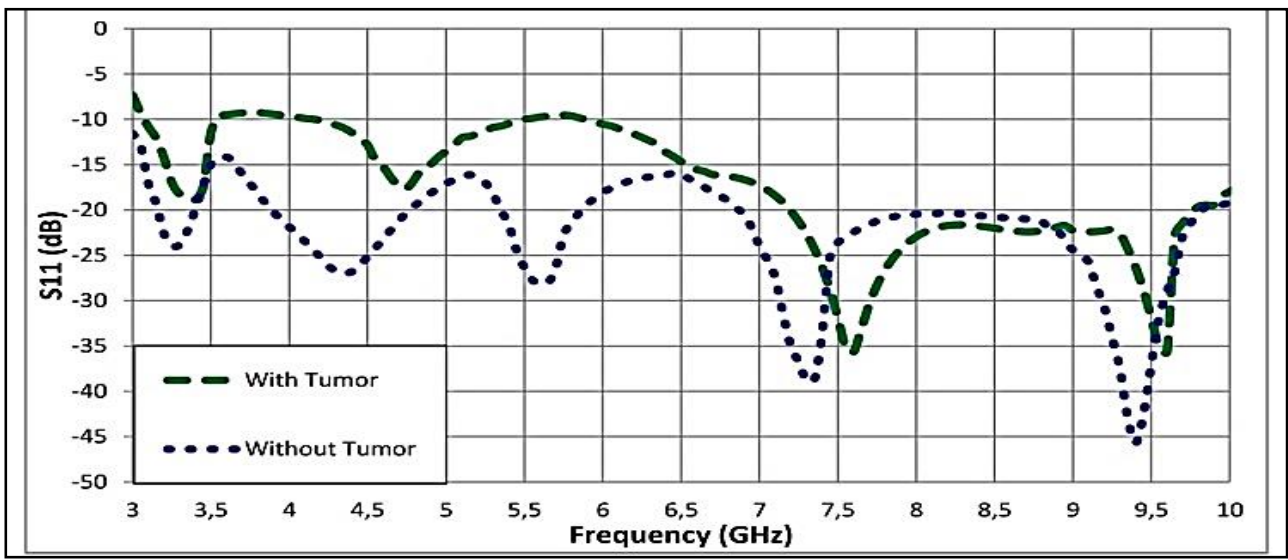

(b)

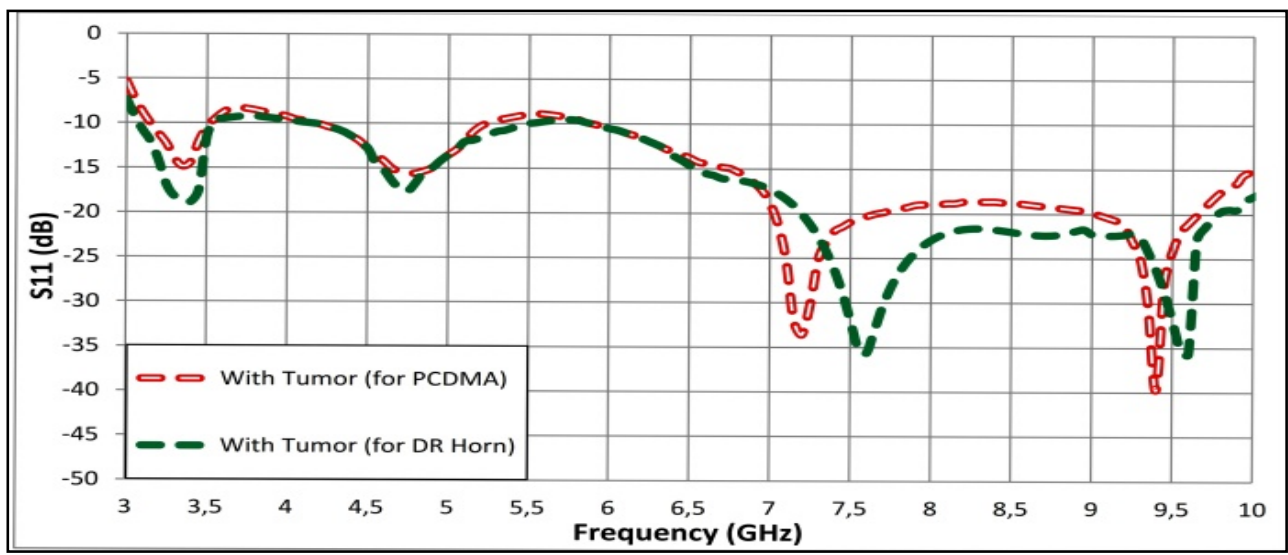

(c)

FIGURE 4. Simulated return loss results:

a) obtained by using PCDMA, b) obtained by using $\mathrm{DRH}, \mathrm{c}$ ) obtained by using both $\mathrm{DRH}$ and PCDMA for tumorous cases. 


\section{B. EXPERIMENTAL MEASUREMENTS AND RESULTS}

As mentioned above, the tumor-mimicking object was located at the center of the phantom and some experimental measurements were made as shown in the previous study [10]. The PCDMA was used in that experiments. In order to prevent reflections from the environment, some absorbers were used during the measurements.
In this study, a similar measurement procedure was repeated by using the DRH antenna in addition to using of the PCDMA. The measurement configuration that contained the VNA, antennae, phantom and absorbers is shown in Fig. 5 (a) as an example. The measured $\mathrm{S}_{11}$ results are compared to each other and given in Fig. 5 (b) and (c), respectively.

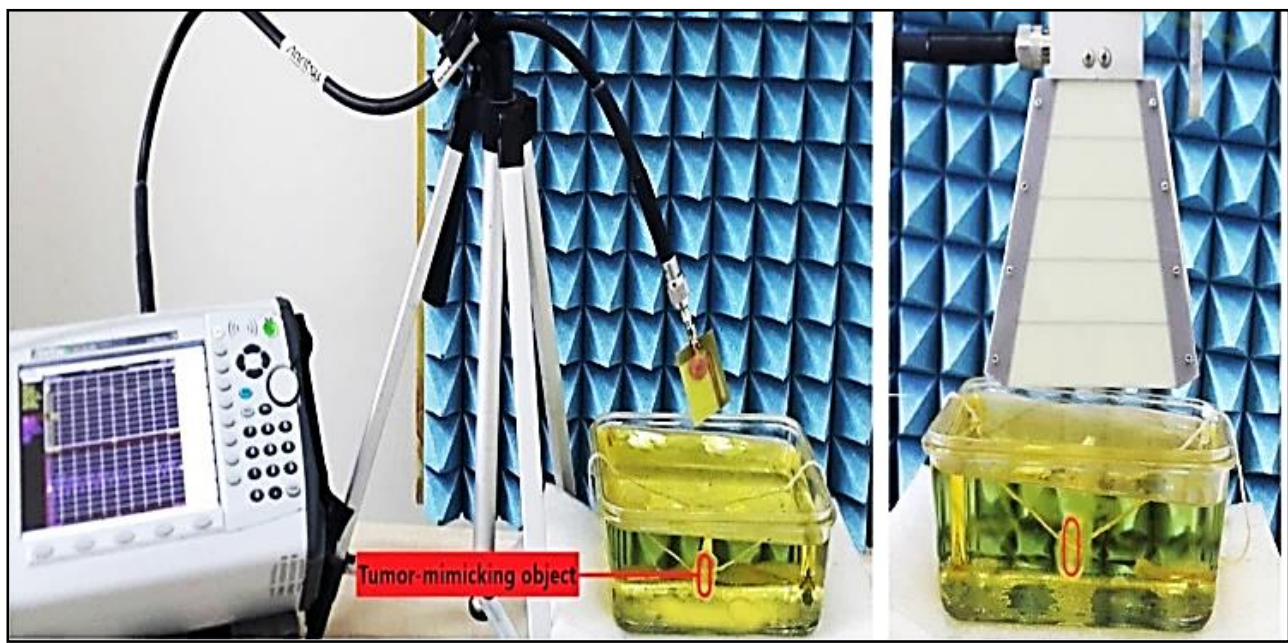

(a)

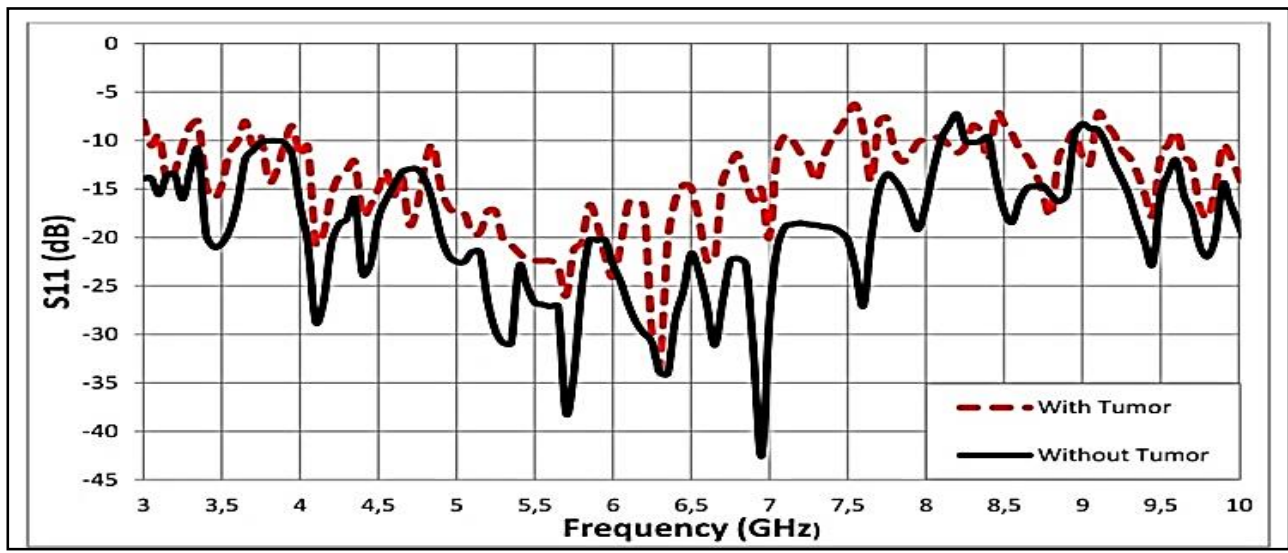

(b)

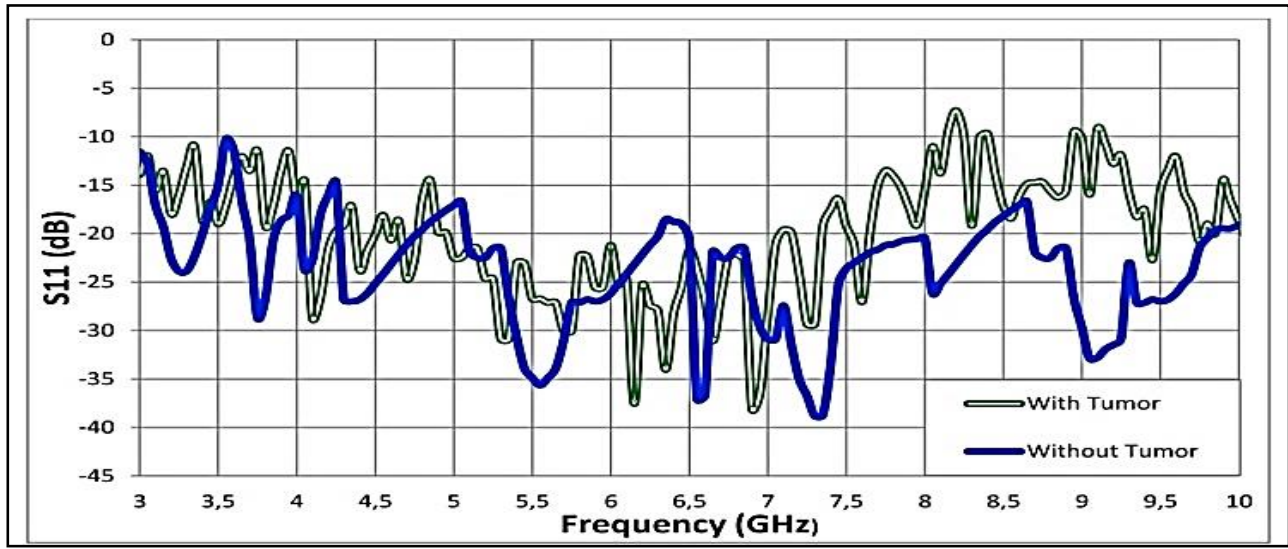

(c) 
a) Measurement system including VNA, phantom and antennas, b) Measured return loss results obtained by using PCDMA,

c) Measured return loss results obtained by using $\mathrm{DRH}$.

In Fig. 5, the results are given for the cases of phantom having a tumor and not having a tumor in it. Additionally, the results obtained by two antennae for only the tumorous cases are plotted at the same graphic in Fig. 6 (a), for comparison purposes. Furthermore, the results that were obtained when the tumor was at the depth of $45 \mathrm{~mm}$ are given in Fig. 6 (b).

\section{DISCUSSIONS}

Since $\mathrm{S}_{11}$ and the reflection coefficient $(\Gamma)$ are related to each other according to (1), the smaller the magnitude of $\mathrm{S}_{11}$, the larger the reflection becomes [42].

$$
S_{11}(d B)=20 \log _{10} \Gamma
$$

It is obviously seen in Fig. 4 and Fig. 5 that the magnitudes of $\mathrm{S}_{11}$ decreased, so the reflections increased when the tumor was present which is an expected situation.
This was because, the $\varepsilon$ and $\sigma$ values of the tumor tissue had much greater values compared to the healthy tissue in the microwave frequencies. So, the presence of the tumor led to an increase in the amount of the reflected wave. The reflection increased again when the tumor was at the depth of $45 \mathrm{~mm}$. However, this time it was not as much as the reflection obtained in the previous measurement. These differences could be observed in Fig. 6 (a) and (b).

Based on the simulated $S_{11}$ results given in Fig. 4 (c) and measured $S_{11}$ results given in Fig. 6 (a) and (b), the reflection differences for the cases of the presence and absence of the tumor were more apparent in the measurements made with the PCDMA than the measurements made with the DRH. In other words, it may be stated that the performance of the monopole antenna was better than the horn antenna for the experiments shown in this study. The reason for this result may be related to the differences between the sizes of these antennae. As mentioned before, the antenna used in radar systems should have a compact-size for focusing to the target material.

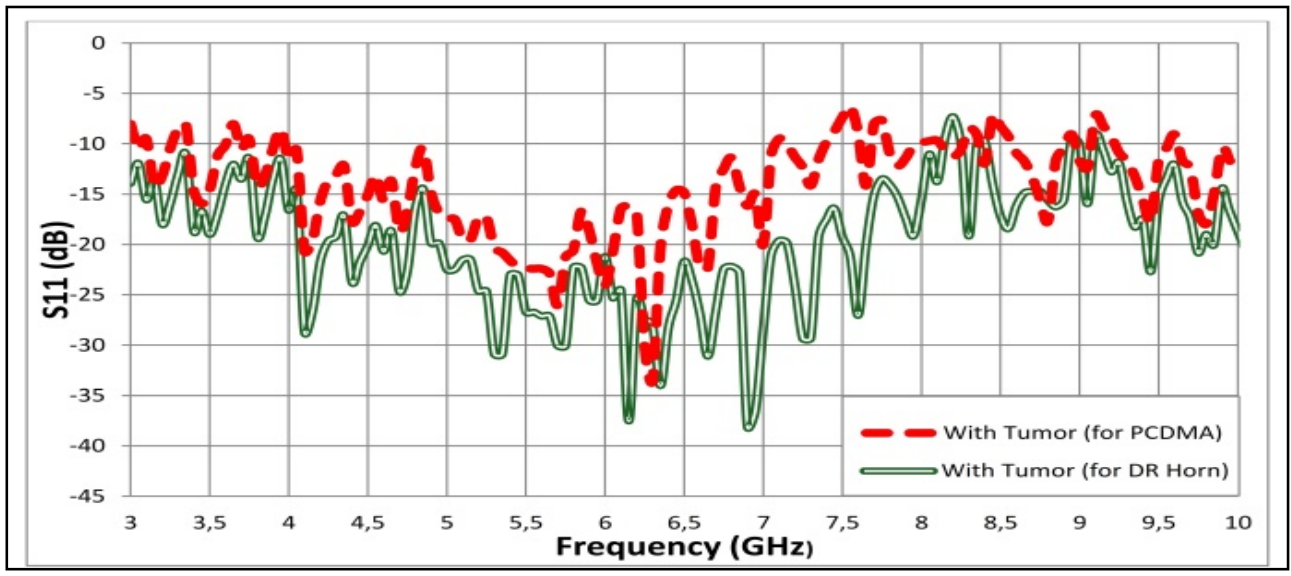

(a)

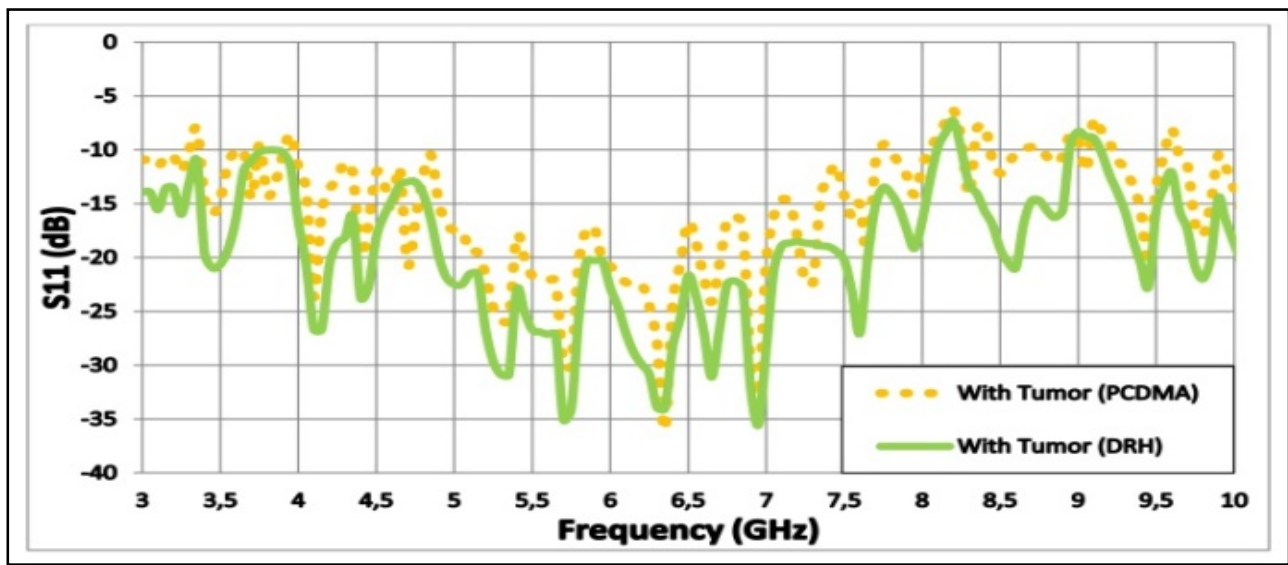

(b)

FIGURE 6. Experimental measurements for tumorous cases:

a) Return loss results obtained by using both DRH and PCDMA, b) Return loss results when the tumor is at the depth of $45 \mathrm{~mm}$. 


\section{CONCLUSION}

This paper reported the performance comparison of a planar monopole antenna to a horn antenna to detect breast cancer tumors by using a radar-based UWB microwave detection system. In order to achieve this aim, simulation and experimental measurements were made in the system including a simple phantom that represented the breast fat and tumor. The simulation measurements were made with the aid of the HFSS program. The experimental measurements were made by using VNA. Based on the obtained results, the reflected energy increased when there was a tumor-mimicking object in the phantom. Thus, it may be stated that the scattering parameters provided important information about the presence of the tumor. Moreover, when the distance between the antenna and tumor decreased, the reflections increased even more. So, an interpretation could be made about the location of the tumor.

In conclusion, it was demonstrated that the performance of the compact-sized antenna was better than that of the largesized antenna for the measurements made in the study. In this paper, the measurements were made in the frequency domain. For observing the results clearly and making a better comparison for the performance of the antennae, it is planned to convert the signals into images in other studies.

\section{ACKNOWLEDGMENT}

This research is related to the Ph.D study of A. R. Celik and supported by the Researching Projects Committee of the University of Dicle (DUBAPK) with the project number MUHENDISLIK.17.011.

\section{REFERENCES}

[1] J. A. Bearden, "X-Ray wavelengths and X-ray atomic energy levels," Reviews of Modern Physics, vol. 39, no. 1, pp. 79-124, 1967.

[2] Institute of Medicine and National Research Council, "Mammography and Beyond: Developing Technologies for the Early Detection of Breast Cancer," Washington, DC: The National Academies Press, 2001. [Online] Available: https://doi.org/10.17226/10030.

[3] S. Vedantham, A. Karellas, G.R. Vijayaraghavan, D.B. Kopans, "Digital breast tomosynthesis: state of the art," Radiology, vol. 277, no. 3, pp. 663-684, 2015.

[4] A. M. Hassan, "Review of electromagnetic techniques for breast cancer detection," IEEE Transactions on Microwave Theory and Techniques, vol. 48, pp. 1854-1863, 2000.

[5] D.B. Kopans, "Breast-cancer screening with ultrasonography," The Lancet, vol. 354, pp. 2096-2097, 1999.

[6] J.P. Stang, "A 3D active microwave imaging system for breast cancer screening", Ph.D. dissertation, The University of Duke, USA, 2014.

[7] E.C. Fear, M.A. Stuchly, "Microwave detection of breast cancer," IEEE Transactions on Microwave Theory and Techniques, vol. 48, pp. 1854-1863, 2000. DOI: $10.1109 / 22.883862$

[8] J.J. Golezani, "Directional wide band printed monopole antenna for use in microwave breast cancer imaging," Ph.D. dissertation, Istanbul Technical University, 2012.
[9] A.R. Celik, M.B Kurt, "Development of a novel ultra-wideband, stable and high directive monopole disc antenna for radar-based microwave imaging of breast cancer," Journal of Microwave Power and Electromagnetic Energy, vol. 52, no. 2, pp. 75-93, 2018.

[10] A. R. Celik, M. B. Kurt and S. Helhel, "An experimental performance investigation of an ultra-wideband directional antenna in the microwave imaging of breast cancer tumor," Applied Computational Electromagnetics Society (ACES) Journal, vol. 34, no. 10, pp. 549-559, 2019.

[11] Amitec Electronics Corp. Innovating Technology 5G Ready, $40 \mathrm{MHz}$ -12.4 GHz RF \& Microwave Antenna Training Lab Sheet.

[12] S. I. Al-Mously, M. M. Abousetta, "A study of the hand on the EM interaction of a cellular handset and a human," World Academy of Science, Engineering and Technology International Journal of Electronics and Communication Engineering, vol. 2, no. 2, 2008.

[13] D. Yin, M.L. Li and J.L. Li, "Non-invasive breast cancer thermotherapy studies using conformal microstrip antennas, in Proc. ISAPE2012, 159-162, 2012.

[14] International Commission on Non-Ionizing Protection (ICNIRP) 1998 - Guidelines for limited exposure to time varying electric, magnetic and electromagnetic fields (up to $300 \mathrm{GHz}$ ), Health Physics, vol. 74, no. 4, pp. 494-522, Apr 1998.

[15] P. Bernardi, M. Cavagnaro, S. Pisa and E. Piuzzi, "Specific absorption rate and temperature elevation in a subject exposed in the far-field of radio-frequency sources operating in the 10-900-mhz range," IEEE Trans. Biomed. Eng., vol. 50, pp. 295-304, 2003.

[16] Y. Li, W. Li and Q, Ye, "A reconfigurable triple notch band antenna integrated with defected microstrip structure band-stop filter for ultra-wideband cognitive radio applications," International Journal of Antennas and Propagation, vol. 2013,Article ID:472645, pp.1-13.

[17] Y. Li, W. Li and W. Yu, "A switchable UWB slot antenna using SISHSIR and SIS-SIR for multi-mode wireless communications applications," Applied Computational Electromagnetics Society (ACES) Journal, vol. 27, no. 4, pp. 340-351, 2012.

[18] Y. Li, W. Li, and Q. Ye, "A compact circular slot UWB antenna with multimode reconfigurable band-notched characteristics using resonator and switch techniques," Microwave and Optical Technology Letters, vol. 56, no. 3, pp. 570-574, 2014.

[19] N. Ojaroudi, M. Ojaroudi, N. Ghadimi, and M. Mehranpour, "UWB square monopole antenna with omni-directional radiation patterns for use in circular cylindrical microwave imaging systems," Applied Computational Electromagnetics Society (ACES) Journal, vol. 28, no. 2, pp. 123-129, 2013.

[20] M. Mokhtaari and J. Bornemann, "Directional ultrawideband antennas in planar technologies," in Proc. 38th European Microwave Conference, Amsterdam, Netherlands, 2008.

[21] A. Locatelli, D. Modotto, F.M. Pigozzo, S. Boscolo, E. Autizi, C.D. Angelis, A.D. Copabianco and M. Midrio, "Highly directional planar ultrawide band antenna for radar applications," in Proc European Microwave Conference, Munich, Germany, 2007.

[22] F. Zhu, S. Gao, A.T.S., T.V.C. Brown, J.Z. Li and J.D. Xu, "Lowprofile directional ultra-wideband antenna for see-through-wall imaging applications," Progress In Electromagnetics Research, vol. 121, pp. 121-139, 2011.

[23] J.J. Golezani, M. Abbak and I. Akduman, "Modified directional wide band printed monopole antenna for use in radar and microwave 1maging applications," Progress In Electromagnetics Research Letters, vol. 33, pp. 119-129, 2012

[24] X. Yun, E.C. Fear and R.H. Johnston, "Compact antenna for radarbased breast cancer detection," IEEE Transactions on Antennas and Propagation, vol. 53, no. 8, pp. 2374-2380, 2005. 
[25] W.C. Khor, M.E. Bialkowski, A. Abbosh, N. Seman and S. Crozier, "An ultra wideband microwave imaging system for breast cancer detection," IEICE Transactions on Communications, vol. E90B, no. 9, pp. 2376-2381, 2007.

[26] M. Bialkowski, Y. Wang, "UWB cylindrical microwave imaging system employing virtual array antenna concept for background effect removal," Microwave and Optical Technology Letters, vol. 53, no. 5, pp. 1100-1104, 2011.

[27] I. Unal, B. Turetken and C. Canbay, "Spherical conformal bowtie antenna for ultrawide band microwave imaging of breast cancer tumor," Applied Computational Electromagnetics Society (ACES) Journal, vol. 29, no. 2, pp. 124-133, 2014.

[28] M.L. Meena, M. Kumar, G. Parmar, R.S. Meena, "Design analysis and modeling of directional UWB antenna with elliptical slotted ground structure for applications in C- \& X-bands," Progress In Electromagnetics Research-C, vol.63, pp.193-207, 2016.

[29] A.M. Abbosh, "Directive antenna for ultrawideband medical imaging systems," International Journal of Antennas and Propagation, vol. 2008, pp.1-6

[30] A.R. Celik, "Simulation measurement for detection of the breast tumors by using ultra-wideband radar-based microwave technique," International Research Journal of Engineering and Technology, vol. 5, no. 11, pp. 1521-1525, 2008.

[31] E. C. Fear, X. Li, S. C. Hagness and M. A. Stuchly, "Confocal microwave imaging for breast cancer detection: localization of tumors in three dimensions," IEEE Transactions on Biomedical Engineering, vol. 49, pp. 812-822, 2002.

[32] S.C. Hagness, A. Taflove and J.E. Bridges, "Three-dimensional FDTD analysis of a pulsed microwave confocal system for breast cancer detection: design of an antenna-array element," IEEE Transactions on Antennas and Propagation, vol.47, pp. 783-791, 1999.

[33] P.M. Meaney, K.D. Paulsen, A. Hartov and R.K. Crane, "An active microwave imaging system for reconstruction of 2-D electrical property distributions," IEEE Transactions on Biomedical Engineering, vol. 42, pp. 1017-1026, 1995.

[34] I. Craddock, R. Nilavalan, J. Leendertz, A. Preece and R. Benjamin, "Experimental investigation of real aperture synthetically organised radar for breast cancer detection", in Proc IEEE on Antennas and
Propagation Society International Symposium, Washington, DC, USA, 2005.

[35] S. Adnan, R.A. Abd-Alhameed, M. Usman, C.H. See, J.M. Noras, and M.B. Child, "Simulation and experimental measurements for near field imaging," in Proc Progress In Electromagnetics Research Symposium, Malaysia, 2012.

[36] J.D. Garrett, E.C. Fear, "Average dielectric property analysis of complex breast tissue with microwave transmission measurements,' Sensors, vol. 15, pp. 1199-1216, 2015.

[37] B.J. Mohammed, "Design and implementation of microwave imaging systems for medical applications," Ph.D. dissertation, The University of Queensland School of Information Technology and Electrical Engineering, Australia, 2014.

[38] M.E. Bialkowski, "Ultrawideband microwave system with novel image reconstruction strategies for breast cancer detection," in Proc. 40th European Microwave Conference, France, 2010.

[39] W.C. Khor, M.E. Bialkowski, "Investigations into cylindrical and planar configurations of a microwave imaging system for breast cancer detection," in Proc. IEEE Antennas and Propagation Society International Symposium, Albuquerque, 2006.

[40] Ansys HFSS. 2014. Ansys Corporation, Canonsburg, USA.

[41] Anritsu Measurement Guide, "Vector network analyzer for Anritsu RF and microwave handheld instruments", Anritsu Company, 2016.

[42] C.A. Balanis, Antenna Theory: Analysis and Design. John Wiley and Sons, New Jersey, USA. 2015. 